\title{
Motility and eosin uptake of formaldehyde-treated ram spermatozoa
}

\author{
O. A. Osinowo, J. O. Bale, E. O. Oyedipe and L. O. Eduvie \\ Department of Animal Reproduction, National Animal Production Research Institute, \\ Ahmadu Bello University, PMB 1096, Zaria, Nigeria
}

\begin{abstract}
Summary. A concentration of $0.005 \%$ formaldehyde in phosphate-buffered saline (PBS) achieved complete immobilization of ram spermatozoa while also yielding good recovery of sperm motility after removal by washing. At a higher formaldehyde concentration $(0.01 \%)$ recovery rate declined with increasing dilution rate.

Incubation of spermatozoa in PBS containing 0.005\% formaldehyde beyond $6 \mathrm{~h}$ at 5,15 or $25^{\circ} \mathrm{C}$ resulted in poor recovery rates. Of the incubation temperatures, eosin uptake was lowest at $25^{\circ} \mathrm{C}$. During 4 h post-wash incubation at $30^{\circ} \mathrm{C}$ sperm motility was significantly $(P<0.001)$ affected by pre-wash formaldehyde concentration which had no effect on the proportion of eosinophilic spermatozoa.
\end{abstract}

\section{Introduction}

The inhibition of sperm motility in formal-saline can be reversed by washing and resuspension in formaldehyde-free diluent (Dott \& Foster, 1975; Dott, Moor \& Polge, 1976). The differential staining of spermatozoa can also be preserved for several days by dilution with formal-citrate (Dott \& Foster, 1975). Fertility was reported in sheep and pigs after insemination with formaldehyde-treated semen (Dott et al., 1976) and it seems that, provided sperm viability can be maintained, formaldehyde treatment may serve as a basis for semen storage.

The present study was designed to investigate the effects of formaldehyde concentration, incubation period and temperature on the reversible inhibition of motility in a phosphatebuffered saline diluent and on eosin uptake by ram spermatozoa.

\section{Materials and Methods}

Semen. Semen was collected by artificial vagina from 3 Yankasa rams for each experiment and pooled. Sperm concentration was determined by means of haemocytometer counts. During the experiments, all samples were coded and randomly presented to an observer for estimations of motility and proportion of eosinophilic spermatozoa.

Diluent. The basic diluent used was a phosphate-buffered saline (PBS) solution, $\mathrm{pH} 7.3$ (Dott, 1975). Calculated amounts of $40 \%$ formaldehyde solution were added to PBS to form PBSF containing the required concentrations of formaldehyde.

Washing. For a washing cycle, diluted semen samples were centrifuged at $684 \mathrm{~g}$ for $10 \mathrm{~min}$ at $25^{\circ} \mathrm{C}$ and the supernatants aspirated. The packed spermatozoa were then resuspended with PBS to the original volume. This procedure was repeated when a second washing was employed. 
Experiments. Six experiments were carried out. In Exp. 1 which was to determine washing efficiency, semen samples were diluted $1: 4$ (semen : diluent, v/v) in triplicates with PBS or PBSF $\left(0.01,0.02\right.$ or $0.04 \%$ formaldehyde) and incubated for $30 \mathrm{~min}$ at $30^{\circ} \mathrm{C}$. The samples were subjected to 2 washing cycles and the supernatants for each washing were re-centrifuged at $25000 \mathrm{~g}$ for $30 \mathrm{~min}$ at $5^{\circ} \mathrm{C}$. The sperm-free supernatants were assayed for extracellular alkaline phosphatase by the method of Bessey, Lowry \& Brock (1946). Washing efficiency was calculated as percentage decrease in extracellular alkaline phosphatase after washing.

In Exp. 2, 4 concentrations of formaldehyde (0, 0.01, 0.02 and $0.04 \%)$ were investigated for the reversible inhibition of sperm motility, using 3 replicates of pooled ram semen. Semen samples were diluted $1: 4$ with PBSF, incubated at $30^{\circ} \mathrm{C}$ for $30 \mathrm{~min}$ and the percentage of motile spermatozoa estimated microscopically at $\times 400$ magnification on pre-warmed slides $\left(37^{\circ} \mathrm{C}\right)$. Samples were washed, incubated at $30^{\circ} \mathrm{C}$ for $30 \mathrm{~min}$ and the motility determined. A second washing was carried out and the samples treated as before.

Experiment 3 was similar to Exp. 2 except that lower concentrations of formaldehyde ( 0 , $0.0025,0.005$ and $0.01 \%$ ) were investigated. Only one washing cycle was used.

Experiment 4 was designed to resolve a conflict in results between Exps 2 and 3 involving $0.01 \%$ formaldehyde (see 'Results'). Three concentrations of formaldehyde $(0,0.005$ and $0.01 \%)$ and 3 dilution rates $(1: 3,1: 5$ and $1: 7)$ were investigated. The pre- and post-wash incubations were for $30 \mathrm{~min}$ at $30^{\circ} \mathrm{C}$. After washing, all samples were resuspended to the same volume as for the $1: 3$ diluted samples.

In Exp. 5, 3 pre-wash incubation temperatures $\left(5,15,25^{\circ} \mathrm{C}\right)$ and 4 pre-wash incubation periods $(2,4,6,8 \mathrm{~h})$ were investigated using PBSF containing $0.005 \%$ formaldehyde only and a dilution rate of $1: 4$ (semen : diluent, $\mathrm{v} / \mathrm{v}$ ). Sample tubes for incubation at $25^{\circ} \mathrm{C}$ were transferred directly to an incubator at that temperature. Other samples were placed in beakers filled with enough water at $30^{\circ} \mathrm{C}$ to achieve cooling to 15 and $5^{\circ} \mathrm{C}$ in $30 \mathrm{~min}$ and $1 \mathrm{~h}$ respectively when placed in incubators at the preset temperatures. After washing, spermatozoa were resuspended with PBS and incubated at $30^{\circ} \mathrm{C}$ for $30 \mathrm{~min}$ before motility estimations. Semen smears stained with eosin-nigrosin were prepared by the method of Dott \& Foster (1972) and the proportion of eosinophilic spermatozoa was determined (100 counts/slide, 3 replicates/treatment) without clearing.

In Exp. 6, the possibility of interaction between formaldehyde concentration and post-wash survival was examined using four concentrations of formaldehyde $(0,0.0025,0.005$ and $0.01 \%)$ and 3 post-wash incubation periods at $30^{\circ} \mathrm{C}(0.5,2$ and $4 \mathrm{~h})$. Dilution rate was $1: 4$ (semen : diluent, $\mathrm{v} / \mathrm{v}$ ). Motility and proportions of eosinophilic spermatozoa were determined at each period of post-wash incubation.

Statistical analysis. The post-wash motility data obtained in Exps 4, 5 and 6 and the differential staining data were analysed by a factorial analysis of variance with a regression approach (Kim \& Kohout, 1975), after angular transformation. The enzyme data were analysed by one-way analysis of variance. Individual comparisons between treatments were by $t$ tests.

\section{Experiment 1}

\section{Results}

The washing efficiencies based on extracellular alkaline phosphatase activities of semen before and after washing are presented in Table 1. Compared to control samples, washing efficiency was significantly higher $(P<0.001)$ in semen samples diluted with PBSF. There were no significant differences amongst the formaldehyde treatments.

\section{Experiment 2}

As shown in Table 2, motility was completely inhibited by the formaldehyde in the PBSF. Some recovery of sperm motility was obtained for semen samples initially diluted with PBSF containing $0.01 \%$ formaldehyde but higher formaldehyde concentrations gave poor recovery of motility even after 2 washings. 
Table 1. Extracellular alkaline phosphatase activities of ram semen samples before and after washing and the calculated washing efficiencies

\begin{tabular}{|c|c|c|c|}
\hline \multirow{2}{*}{$\begin{array}{l}\% \text { formaldehyde } \\
\text { in diluent }\end{array}$} & \multicolumn{2}{|c|}{$\begin{array}{l}\text { Alkaline phosphatase } \\
\text { (i.u. } / 10^{9} \text { spermatozoa) }\end{array}$} & \multirow{2}{*}{$\begin{array}{c}\text { Washing } \\
\text { efficiency }(\%) \ddagger\end{array}$} \\
\hline & Before washing* & After washing $\dagger$ & \\
\hline 0 (control) & $1.67 \pm 0.08^{a}$ & $0.17 \pm 0^{c}$ & $89.8 \pm 0.5^{e}$ \\
\hline 0.01 & $1.96 \pm 0.03^{b}$ & $0.09 \pm 0^{d}$ & $95.5 \pm 0.2^{f}$ \\
\hline 0.02 & $1.78 \pm 0.07^{\mathrm{a}}$ & $0.09 \pm 0.01^{d}$ & $94.9 \pm 0.3^{f}$ \\
\hline 0.04 & $1.70 \pm 0.03^{a}$ & $0.09 \pm 0.01^{d}$ & $94.9 \pm 0.4^{f}$ \\
\hline
\end{tabular}

Values are mean \pm s.e.m. for 3 replicates. Means in the same column with different superscripts are significantly different $(P<0.05)$.

* Supernatant removed after the first centrifugation.

† Supernatant removed after redilution and centrifugation.

$\ddagger$ Percentage decrease in extracellular activity.

Table 2. Effects of formaldehyde concentration and number of washings on sperm motility

\begin{tabular}{cccc}
\hline & \multicolumn{3}{c}{$\%$ motile spermatozoa } \\
\cline { 2 - 4 } $\begin{array}{c}\text { \% formaldehyde } \\
\text { in PBSF }\end{array}$ & $\begin{array}{c}\text { Before } \\
\text { washing }\end{array}$ & 1st washing & 2nd washing \\
\hline 0 (control) & $95.0 \pm 0$ & $91.7 \pm 1.7$ & $81.7 \pm 3.3$ \\
0.01 & 0 & $53.3 \pm 16.4$ & $55.0 \pm 5.8$ \\
0.02 & 0 & $1.7 \pm 1.7$ & $8.3 \pm 1.7$ \\
0.04 & 0 & 0 & $3.3 \pm 1.7$ \\
\hline
\end{tabular}

Values are mean \pm s.e.m. for 3 replicates.

\section{Experiment 3}

Motility was partly inhibited by $0.0025 \%$ formaldehyde but was completely inhibited by higher concentrations (Table 3 ). Post-wash motility was high in the spermatozoa kept in $0.005 \%$ formaldehyde but there was no recovery of motility in the $0.01 \%$ formaldehyde, contrasting with results for the same concentration of formaldehyde in Exp. 2. The sperm concentrations after dilution in Expts 2 and 3 were 7.29 and $6.14 \times 10^{8}$ spermatozoa $/ \mathrm{ml}$ respectively and the difference in sperm concentration could have accounted for the different results.

Table 3. Effect of low levels of formaldehyde on sperm motility

\begin{tabular}{lcc}
\hline & \multicolumn{2}{c}{$\%$ motile spermatozoa } \\
\cline { 2 - 3 } $\begin{array}{c}\text { \% formaldehyde } \\
\text { in PBSF }\end{array}$ & $\begin{array}{c}\text { Before } \\
\text { washing }\end{array}$ & $\begin{array}{c}\text { After } \\
\text { washing }\end{array}$ \\
\hline 0 (control) & $95.0 \pm 0$ & $78 \cdot 3 \pm 4.4$ \\
0.0025 & $58.3 \pm 7.3$ & $75.0 \pm 5 \cdot 0$ \\
0.005 & 0 & $66.7 \pm 11.7$ \\
0.01 & 0 & 0 \\
\hline
\end{tabular}

Values are means \pm s.e.m. for 3 replicates. 


\section{Experiment 4}

Motility was abolished by 0.005 and $0.01 \%$ formaldehyde, irrespective of dilution rate (Table 4). Although motile spermatozoa were observed after washing in all cases, there was a significant interaction $(P<0.001)$ between formaldehyde concentration and dilution rate, due mainly to the decline in recovery rate with increasing dilution with $0.01 \%$ formaldehyde. Differences in recovery rates between formaldehyde treatments were significant $(P<0.001)$.

Table 4. Effect of formaldehyde concentration and dilution rate on sperm motility

\begin{tabular}{cccc}
\hline \multirow{2}{*}{$\begin{array}{c}\text { \% formaldehyde } \\
\text { in PBSF }\end{array}$} & $\begin{array}{c}\text { Pre-wash } \\
\text { dilution rate } \\
\text { (semen : diluent, v/v) }\end{array}$ & $\begin{array}{c}\text { \% motile spermatozoa } \\
\text { Before }\end{array}$ & $\begin{array}{c}\text { After } \\
\text { washing }\end{array}$ \\
\hline 0 (control) & $1: 3$ & $88 \cdot 3 \pm 1 \cdot 7$ & $85 \cdot 0 \pm 2.9$ \\
& $1: 5$ & $90.0 \pm 5.0$ & $91.7 \pm 1.7$ \\
0.005 & $1: 7$ & $95.0 \pm 0$ & $88.3 \pm 4.4$ \\
& $1: 3$ & 0 & $65.0 \pm 7.6$ \\
0.01 & $1: 5$ & 0 & $48.3 \pm 4.4$ \\
& $1: 7$ & 0 & $58.3 \pm 6.7$ \\
& $1: 3$ & 0 & $58.3 \pm 6.7$ \\
& $1: 5$ & 0 & $38.3 \pm 4.4$ \\
& $1: 7$ & 0 & $13.3 \pm 6.0$ \\
\hline
\end{tabular}

Values are mean \pm s.e.m. for 3 replicates.

\section{Experiment 5}

Motility after washing was not significantly affected by the pre-wash incubation temperature (Table 5 ) but was significantly altered $(P<0.001)$ by the pre-wash incubation period, mainly

Table 5. Effects of incubation period and temperature on the motility and eosin uptake of formaldehydetreated spermatozoa $(0.005 \%)$

\begin{tabular}{|c|c|c|c|}
\hline \multicolumn{2}{|c|}{ Pre-wash incubation } & \multirow{2}{*}{\multicolumn{2}{|c|}{$\%$ spermatozoa after washing }} \\
\hline \multirow{2}{*}{$\begin{array}{l}\text { Temperature } \\
\left({ }^{\circ} \mathrm{C}\right)\end{array}$} & \multirow{2}{*}{$\begin{array}{l}\text { Period } \\
\text { (h) }\end{array}$} & & \\
\hline & & Motile & Stained \\
\hline 5 & $\begin{array}{l}2 \\
4 \\
6 \\
8\end{array}$ & $\begin{array}{l}28 \cdot 3 \pm 1.7 \\
30 \cdot 0 \pm 7.6 \\
30 \cdot 0 \pm 0 \\
10 \cdot 0 \pm 5.0\end{array}$ & $\begin{array}{l}23 \cdot 7 \pm 4 \cdot 1 \\
26 \cdot 7 \pm 4 \cdot 7 \\
31 \cdot 0 \pm 3 \cdot 0 \\
30 \cdot 3 \pm 1.2\end{array}$ \\
\hline 15 & $\begin{array}{l}2 \\
4 \\
6 \\
8\end{array}$ & $\begin{array}{l}31.7 \pm 4.4 \\
30.0 \pm 0 \\
28.3 \pm 4.4 \\
5.0 \pm 2.9\end{array}$ & $\begin{array}{l}33 \cdot 3 \pm 5 \cdot 8 \\
28 \cdot 3 \pm 0 \cdot 7 \\
44 \cdot 3 \pm 2 \cdot 3 \\
38 \cdot 7 \pm 4 \cdot 1\end{array}$ \\
\hline 25 & $\begin{array}{l}2 \\
4 \\
6 \\
8\end{array}$ & $\begin{array}{r}38.3 \pm 7.3 \\
28.3 \pm 6.0 \\
21.7 \pm 4.4 \\
3.3 \pm 1.7\end{array}$ & $\begin{array}{l}23 \cdot 7 \pm 7 \cdot 1 \\
22 \cdot 3 \pm 2 \cdot 8 \\
15 \cdot 3 \pm 2 \cdot 2 \\
20 \cdot 7 \pm 4 \cdot 7\end{array}$ \\
\hline
\end{tabular}

Values are mean \pm s.e.m. for 3 replicates. 
because of the sharp decline in recovery beyond $6 \mathrm{~h}$. By contrast the proportion of eosinophilic spermatozoa was significantly $(P<0.001)$ affected by pre-wash incubation temperature but not by incubation period. The proportions (\%) of eosinophilic spermatozoa at 5,15 and $25^{\circ} \mathrm{C}$ were (mean \pm s.e.m., $n=12$ ): $27 \cdot 9 \pm 1 \cdot 7,36 \cdot 2 \pm 2 \cdot 4$ and $20 \cdot 5 \pm 2 \cdot 2 \%$ respectively.

\section{Experiment 6}

Formaldehyde concentration and post-wash incubation period significantly $(P<0.001)$ affected motility but neither had any effect on eosin uptake (Table 6). There was a significant $(P<0.001)$ interaction between formaldehyde concentration and incubation period with respect to motility, due to late sperm motility recovery (highest motility at $2 \mathrm{~h}$ ) in the $0.01 \%$ formaldehyde group.

Table 6. Effects of formaldehyde concentration and postwash incubation period on the motility and eosin uptake of spermatozoa

\begin{tabular}{|c|c|c|c|}
\hline \multirow{2}{*}{$\begin{array}{l}\text { \% formaldehyde } \\
\text { in PBSF }\end{array}$} & \multirow{2}{*}{$\begin{array}{l}\text { Post-wash } \\
\text { incubation } \\
\text { period (h) }\end{array}$} & \multicolumn{2}{|c|}{$\%$ spermatozoa after washing } \\
\hline & & Motile & Stained \\
\hline 0 (control) & $\begin{array}{l}0.5 \\
2.0 \\
4.0\end{array}$ & $\begin{array}{l}53 \cdot 3 \pm 4.4 \\
46 \cdot 7 \pm 1 \cdot 7 \\
45 \cdot 0 \pm 2.9\end{array}$ & $\begin{array}{l}21 \cdot 3 \pm 1.9 \\
28 \cdot 3 \pm 2.9 \\
28.0 \pm 4.0\end{array}$ \\
\hline 0.0025 & $\begin{array}{l}0.5 \\
2 \cdot 0 \\
4 \cdot 0\end{array}$ & $\begin{array}{r}40.0 \pm 2.9 \\
18 \cdot 3 \pm 6 \cdot 0 \\
6.7 \pm 4.4\end{array}$ & $\begin{array}{l}29 \cdot 3 \pm 2 \cdot 6 \\
33 \cdot 7 \pm 4 \cdot 7 \\
35 \cdot 3 \pm 4.4\end{array}$ \\
\hline 0.005 & $\begin{array}{l}0.5 \\
2 \cdot 0 \\
4 \cdot 0\end{array}$ & $\begin{array}{r}41.7 \pm 1.7 \\
28 \cdot 3 \pm 6 \cdot 0 \\
8.3 \pm 1.7\end{array}$ & $\begin{array}{l}32 \cdot 3 \pm 2 \cdot 3 \\
25 \cdot 0 \pm 1 \cdot 0 \\
29 \cdot 3 \pm 1 \cdot 8\end{array}$ \\
\hline 0.01 & $\begin{array}{l}0.5 \\
2 \cdot 0 \\
4 \cdot 0\end{array}$ & $\begin{array}{l}5 \cdot 0 \pm 0 \\
23 \cdot 3 \pm 1 \cdot 7 \\
15 \cdot 0 \pm 0\end{array}$ & $\begin{array}{l}29.3 \pm 1.9 \\
28.7 \pm 5.2 \\
29.3 \pm 1.8\end{array}$ \\
\hline
\end{tabular}

Values are mean \pm s.e.m. for 3 replicates.

\section{Discussion}

The present study confirms the report by Dott et al. (1976) on the reversibility of the inhibition of sperm motility in formal-saline diluents by washing. Our results show sperm recovery rates to be dependent on pre-wash formaldehyde concentration, dilution rate with formaldehydecontaining diluent, and pre- and post-wash incubation periods. Eosin uptake by formaldehyde-treated spermatozoa was mainly influenced by incubation temperature during incubation for $8 \mathrm{~h}$.

Over $90 \%$ of the extracellular fluid of sperm suspensions was removed by washing in the present study, permitting the resumption of motility by immobilized spermatozoa as a result of the removal of formaldehyde. The higher washing efficiencies obtained with semen diluted with PBSF over control samples was due to better cell packing by non-motile spermatozoa which allowed for more complete aspiration of supernatant. The immobilization of spermatozoa became progressively irreversible with increasing formaldehyde concentration. While motility was only partly inhibited by $0.0025 \%$ formaldehyde, it was reversibly inhibited by 0.005 and 
$0.01 \%$ formaldehyde. Inhibition of sperm motility was virtually irreversible at a concentration of $0.04 \%$ formaldehyde. The interaction obtained in Exp. 6 between pre-wash formaldehyde concentration and sperm motility during post-wash incubation period could have resulted from greater penetration of spermatozoa by formaldehyde at the higher concentrations which required more time to diffuse out from the cells after washing and resuspension. The optimum formaldehyde concentration for the reversible inhibition of sperm motility in the present study was $0.005 \%$. However, it is possible that a different result would be obtained if a more efficient washing method was used (see Harrison, 1976).

The mechanism of action of formaldehyde on spermatozoa is not fully understood. At the molecular level formaldehyde reacts with the amino groups of proteins and amino acids resulting in methylene linkages (Herriott, 1947). It causes protein denaturation and losses in the activities of enzymes (Hopwood, 1967). At the cellular level, it has been postulated that formaldehyde exerts a stabilizing effect on sperm membranes, preventing damage (Dott et al., 1976). In experiments with ram semen, formaldehyde acted as a metabolic inhibitor, curtailing oxygen uptake by spermatozoa at a concentration of $0.005 \%$ in PBS (O. A. Osinowo, unpublished).

It appears from the results of Exps 5 and 6 that the differential staining of spermatozoa is maintained for a longer period than is motility after the removal of formaldehyde by washing, but the duration of preservation of sperm fertility after formaldehyde treatment is not known. It is also possible that diluents other than PBS may preserve spermatozoa better in the presence of formaldehyde. This needs to be investigated in view of the decline in sperm motility after pre-wash incubations of $>6 \mathrm{~h}$ (Exp. 5). Fertility has been reported in ewes inseminated with semen to which formaldehyde had been added 2 min before insemination and in sows with semen similarly treated 1 or $2 \mathrm{~h}$ before insemination (Dott et al., 1976). It seems likely, however, that sperm viability will have to be demonstrated beyond a few days before formaldehyde treatment can become an acceptable method of semen preservation.

We are grateful to $\mathrm{Mr}$ J. Ogbonna and $\mathrm{Mr} \mathrm{M}$. Eduvie for technical help.

\section{References}

Bessey, O.A., Lowry, O.H. \& Brock, M.J. (1946) A method for the rapid determination of alkaline phosphatase with five cubic millimeters of serum. $J$. biol. Chem. 164, 321-329.

Dott, H.M. (1975) The estimation of the proportion of motile bull spermatozoa in various diluents and a comparison with the proportion eosinophilic. $J$. Reprod. Fert. 45, 47-55.

Dott, H.M. \& Foster, G.C. (1972) A technique for studying the morphology of mammalian spermatozoa which are eosinophilic in a differential 'live/ dead' stain. J. Reprod. Fert. 29, 443-445.

Dott, H.M. \& Foster, G.C. (1975) Preservation of differential staining of spermatozoa by formol citrate. J. Reprod. Fert. 45, 47-60.

Dott, H.M., Moor, R.M. \& Polge, C. (1976) Artificial insemination with spermatozoa in formaldehyde. $J$. Reprod. Fert. 46, 277.
Harrison, R.A.P. (1976) A highly efficient method for washing mammalian spermatozoa. $J$. Reprod. Fert. 48, 347-353.

Herriott, R.M. (1947) Reactions of native proteins with chemical reagents. Adv. Protein Chem. 3, 169-225.

Hopwood, D. (1967) Some aspects of fixation with glutaraldehyde: A biochemical and histological comparison of the effects of formaldehyde and glutaraldehyde fixation on various enzymes and glycogen, with a note on penetration of glutaraldehyde into liver. J. Anat. 101, 83-92.

Kim, J. \& Kohout, F.J. (1975) Analysis of variance and covariance: subprograms ANOVA and One-way. In Statistical Package for the Social Sciences, 2nd edn, pp. 398-433. Eds N. H. Nie, C. H. Hull, J. G. Jenkins, K. Steinbrenner \& D. H. Bent. McGrawHill, New York. 